\title{
Spinal abnormalities and the atypical form of the Mayer-Rokitansky-Küster-Hauser syndrome
}

\author{
Ernst H. Strübbe ${ }^{1}$, J. Albert M. Lemmens ${ }^{2}$, Cornelis J.P. Thijn ${ }^{3}$, Wim N.P. Willemsen ${ }^{4}$, Bert S.J. van Toor ${ }^{5}$
}

Skeletal Radiol (1992) 21:459-462

The authors of the above article would like to make the following corrections:

p. 460, Table 1, line 8, 3rd column: Spina bifida occulta

Table 1. Spinal anomalies as radiographic finding in 96 patients with Mayer-Rokitansky-Küster-Hauser (MRKH) syndrome

\begin{tabular}{|c|c|c|c|c|}
\hline \multirow[t]{3}{*}{ Anomalies } & \multicolumn{4}{|c|}{ Number of features } \\
\hline & \multicolumn{2}{|c|}{$\begin{array}{l}\text { Patients with } \\
\text { atypical MRKH } \\
(N=52)\end{array}$} & \multicolumn{2}{|c|}{$\begin{array}{l}\text { Patients with } \\
\text { typical MRKH } \\
(N=44)\end{array}$} \\
\hline & $n$ & $\%$ & $n$ & $\%$ \\
\hline KF syndrome & 14 & 26.9 & - & \\
\hline subtype 1 & 5 & 9.6 & - & \\
\hline subtype 2 & 6 & 11.5 & - & \\
\hline subtype 3 & 3 & 5.8 & 一 & \\
\hline Scoliosis & 10 & 19.2 & - & \\
\hline Sacral agenesis & 2 & 3.9 & - & \\
\hline Sacralization L5 & 5 & 9.6 & 1 & 2.3 \\
\hline Spina bifida occulta & 25 & 48.1 & 4 & 9.1 \\
\hline Fusion L2-3 & 1 & 1.9 & - & \\
\hline No. of patients & 37 & 71.2 & 5 & 11.4 \\
\hline
\end{tabular}

a Fifty-seven features were found in 37 patients. Scoliosis combined with Klippel-Feil (KF) syndrome was found in 8 patients, while spina bifida occulta in combination with $\mathrm{KF}$ syndrome was seen in 12 patients. p. 461 , left column, lines 28 and 29 :

The incidence of spina bifida occulta in the typical group is only slightly higher than .... 